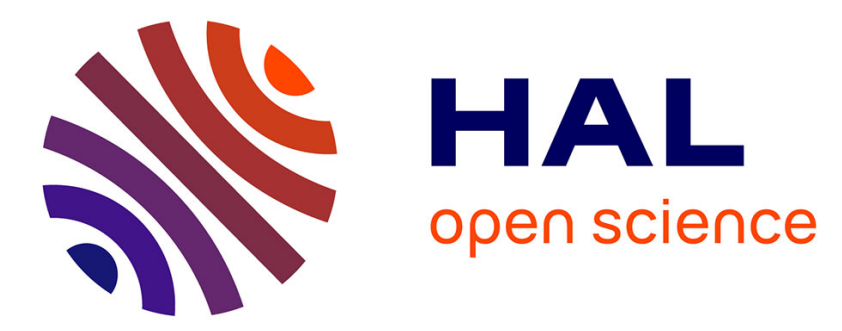

\title{
A Thermo-Metallurgical Model for Steel Cooling Behaviour : Proposition, Validation and Comparison with the Sysweld's Model
}

\author{
F. Waeckel, P. Dupas, S. Andrieux
}

\section{- To cite this version:}

F. Waeckel, P. Dupas, S. Andrieux. A Thermo-Metallurgical Model for Steel Cooling Behaviour: Proposition, Validation and Comparison with the Sysweld's Model. Journal de Physique IV Proceedings, 1996, 06 (C1), pp.C1-255-C1-264. 10.1051/jp4:1996125 . jpa-00254157

\section{HAL Id: jpa-00254157 https://hal.science/jpa-00254157}

Submitted on 1 Jan 1996

HAL is a multi-disciplinary open access archive for the deposit and dissemination of scientific research documents, whether they are published or not. The documents may come from teaching and research institutions in France or abroad, or from public or private research centers.
L'archive ouverte pluridisciplinaire $\mathbf{H A L}$, est destinée au dépôt et à la diffusion de documents scientifiques de niveau recherche, publiés ou non, émanant des établissements d'enseignement et de recherche français ou étrangers, des laboratoires publics ou privés. 


\title{
A Thermo-Metallurgical Model for Steel Cooling Behaviour: Proposition, Validation and Comparison with the Sysweld's Model
}

\author{
F. Waeckel, P. Dupas* and S. Andrieux \\ Département Mécanique et Modèles Numériques, E.D.F. Etudes et Recherches, 92141 Clamart, France \\ * Département Mécanique et Technologie des Composants, E.D.F. Etudes et Recherches, \\ 77250 Moret-sur-Loing, France
}

\begin{abstract}
: the aim of this work is to include the metallurgical behaviour of steels (and specifically their phase transformations) into thermo-mechanical studies. In this purpose, a new model of anisothermal phase transformations during the cooling stage is proposed. Developed in the thermodynamics framework of simple materials with memory variables, its originality lies in the choice of the temperature time derivative $\dot{T}$ as an independent variable. The identification and the transformation rates computation use the CCT diagrams which are considered as families of particular solutions of evolution equations. The validation shows ability of the model to simulate all CCT deductible tests. Furthermore, for some tests not included into the CCT the numerical results remain good and the model, from which evolution equation form as been let free, allows to incorporate them to the identification data without modifying the CCT simulation accuracy. Lastly, for all the previous tests, this model has been compared with the one of the Sysweld software.
\end{abstract}

\section{INTRODUCTION}

Many studies of nuclear components, involving for instance dissimilar joints or underclad defects, require the numerical simulation of thermo-metallurgical phenomena caused by heat treatment or welding in order to determine the residual stress field.

Although no exhaustive theoretical modelling of anisothermal phases transformations has been attempted, there are a number of metallurgical behaviour models enabling calculation of residual stresses [6-7-8-11]. However, the extent to which the observed metallurgical response of steels is affected by their entire thermal history is generally overlooked in the initial formulation of these models. And their identification is also problematic, making then difficult to adapt to each new steel.

With a view to integrating the effect of thermal history on metallurgical behaviour, the model presented has been developed in the framework of thermodynamics of materials with internal state variables including the cooling rate $\dot{\mathrm{T}}$ among its variables. Although unusual, introducing this variable would not appear to be thermodynamically illicit and the model built and developed for cooling stage can also be applied for heating [14]. In addition, since it seemed difficult to propose a simple form of model dependence on $\dot{T}$, it was decided to impose no specific form for the metallurgical internal variable evolution equations. Calculation of the metallurgical evolution rates is then based on the fact that any known experimental history can be interpreted as a particular solution to the differential evolution equations. Finally, the options selected have the advantage of enabling simple and fast identification of the model and data preparation requiring only CCT diagrams (Continuous Cooling Transformations). Despite uncertainties as to the absolute representativeness of these diagrams, the validation elements presented are most encouraging and the model has been inserted in an industrial finite element code.

\section{PROPOSITION OF THE MODEL}

\subsection{Hypothesis}

As suggested by the dilatometric tests and in accordance with common approach, we choose to describe 
the metallurgical structure at a given material point by the quantity $\mathbf{Z}=\left(\mathrm{Z}_{1}, \mathrm{Z}_{2}, \mathrm{Z}_{3}, \mathrm{Z}_{4}\right)$, which components are the respective proportions of ferrite, pearlite, bainite and martensite.

Then, to include a memory effect of time-temperature history on metallurgical evolutions we choose to develop the model in the framework of thermodynamics of simple materials with memory variables [312]. Furthermore, to take into account a cooling rate effect on the structural evolutions we include, from the beginning, the temperature time derivative $T$ as an independent variable.

We suppose then that the structural transformation rate $\dot{Z}(M, t)$ is an explicit function of the values at $\mathbf{M}$ and $t$ of the pilot state variables $\mathbf{p}(\mathbf{M}, t)$, some of their first time derivatives $\dot{p}(M, t)$ and other internal state variables $\eta(M, t)$, the evolution rates of which are also explicit functions of $\mathbf{p}(\mathbf{M}, t), \dot{\mathbf{p}}(\mathbf{M}, t)$ and $\eta(M, t)$. Thus the first assumption can be written :

$$
\text { HI : } \quad \dot{\mathrm{Z}}=\boldsymbol{f}\left(\mathrm{p}, \dot{\mathrm{p}}, \mathbf{Z}, \eta_{\mathrm{k}}\right) \quad \text { and } \quad \dot{\eta}_{\mathrm{k}}=\psi_{\mathrm{k}}\left(\mathrm{p}, \dot{\mathrm{p}}, \mathbf{Z}, \eta_{\mathrm{k}}\right)
$$

To make more precise the choice of the pilot and internal variables, as the form of the evolution functions, we make two other hypothesis.

H2 : The CCT diagrams, supplemented with the Koïstinen-Marbürger (2) martensitic transformation kinetics totally characterise the metallurgical behaviour of an austenitized steel during continuous cooling.

This hypothesis, deriving directly from metallurgical practice, also fulfils the objective of obtaining an industrial-scale model, requiring for its identification only easily available experimental data.

H3 : Ferritic, pearlitic and especially bainitic transformations cannot take place below the martensite starting temperature $M$ s.

With this hypothesis, compliant with CCT diagram representations, transformations by diffusion can be separated from the martensitic transformation.

\subsection{State variables choice}

- Pilot state variables : in continuum thermomechanics, the pilot state variables are generally temperature and stress or strain state. However, according with hypothesis $\boldsymbol{H 2}$, temperature is the only pilot variable actively involved in metallurgical variable evolution functions. Indeed, the effect of the stress state on structural transformations (which is not zero [1]) is not shown in the CCT diagrams.

- Memorising state variables : the first memorising variable to be introduced is the quadruplet $\mathbf{Z}$, which characterises the metallurgical structure and enables mechanical description of a dilatometric test.

In addition, apart from the temperature, its time derivative $\dot{T}$ and the stress state, the austenitic grain size $d$ and the transforming austenite carbon content $\mathrm{C}$ also affect the metallurgical behaviour of steels during cooling. However, because carbon diffusion is not explicitly shown on the CCT diagrams, $\mathrm{C}$ is not introduced as a internal variable.

Unlike the carbon content, the austenitic grain size is related to the austenitization conditions shown on CCT diagrams. But $d$ only results from the heating and is consequently simply introduced as a parameter in the cooling behaviour model presented here. Nevertheless, $d$ can be used in future to take into account more than one CCT diagram.

Lastly, due to the austenite stabilisation phenomenon, the martensite starting temperature Ms, present in the Koïstinen-Marbürger law depends on the thermo-metallurgical history. It is consequently introduced as a memorising variable.

To model all the phenomena brought into play during a welding operation, we have also to include other memorising variables like anelastic strain tensors $\varepsilon^{\text {an }}$, corresponding to plastic strains, transformation plasticity or viscosity. However, according with hypothesis $\boldsymbol{H 2}$, these variables will no affect the $\mathbf{Z}$ and Ms evolution functions. 
Thus, with the hypothesis and variables adopted, we obtain :

$$
\begin{aligned}
& \dot{\mathbf{z}}(\mathrm{t})=\boldsymbol{f}(\mathrm{T}, \dot{\mathrm{T}}, \mathbf{z}, \mathrm{Ms} ; d)=f(\mathrm{~T}, \dot{\mathrm{T}}, \mathbf{z} ; d) \frac{[\mathrm{T}-\mathrm{Ms}]^{+}}{\mathrm{T}-\mathrm{Ms}} \quad \text { with } \mathbf{z}=\left\{\mathrm{Z}_{1}, \mathrm{Z}_{2}, \mathrm{Z}_{3}\right\} \\
& \mathrm{Z}_{4}(\mathrm{~T}, \mathrm{z}, \mathrm{Ms} ; d)=\left[1-\sum_{\mathrm{i}=1}^{\mathrm{i}=3} \mathrm{Z}_{\mathrm{i}}\right]\left\{1-\exp \left(\beta(d)[\mathrm{Ms}-\mathrm{T}]^{+}\right)\right\} \\
& \text {where } \beta\left({ }^{\circ} \mathrm{C}^{-1}\right) \text { is a material parameter and }[\mathrm{X}]^{+} \text {is the positive part of } \mathrm{X} . \\
& \text { and } \mathrm{Ms}(\mathrm{z} ; d)=\mathrm{Ms}_{0}(d)+\mathrm{A}(d)\left[\sum_{\mathrm{i}=1}^{\mathrm{i}=3} \mathrm{Z}_{\mathrm{i}}-\mathrm{Z}^{\mathrm{s}}(d)\right]^{+}
\end{aligned}
$$

For a given grain size, Ms is thus assumed to be constant and equal to $\mathrm{Ms}_{0}$ as long as the proportion of transformed austenite remains below a threshold $\mathrm{Z}^{\mathrm{S}}$. Its subsequent variation is then assumed to be a linear function of the quantity of transformed austenite. These assumptions would appear to be fairly well corroborated by experimental data.

\subsection{Form of the evolution function}

Although unusual, introducing $\dot{T}$ as a true variable would not appear to be thermodynamically illicit and this model built and developed for cooling can also be generalise to heating [14]. Furthermore, we have seen that it seemed difficult to propose, based on physical mechanism or thermodynamics formalism, a simple form of model dependence on $\mathrm{T}$. That is why it was decided to impose no specific form for the metallurgical internal variable evolution equations and to use, for the calculation of the metallurgical evolution rates, the known values of the evolution function derived from the CCT diagrams. Indeed, this diagrams constitute a set of time-temperature histories for which the metallurgical evolutions $\mathbf{Z}(\mathrm{T}(\mathrm{t}))$ are known and are each one a particular solution of evolution equations. In the framework of the model, time differentiation of these experimental $\mathbf{Z}(\mathrm{T}(\mathrm{t}))$ evolutions gives then rise to the knowledge of a set $E$ of the value of the $f$ function for every state $\{\mathrm{T}, \mathrm{T}, \mathrm{z} ; d\}$ found in CCT diagrams. Thus, for any thermal loading, we evaluate the rate of transformations for a given state using some special interpolation technique in the set $E$ (where the states are now independent), without imposing any restrictions on the form of the $f$ function.

\section{IDENTIFICATION OF THE MODEL}

\subsection{Identification of the martensitic transformation model}

The martensitic transformations are assumed to be described by the Koïstinen-Marbürger law (2) and the phenomenological equation (3) expressing Ms. Then, each CCT diagram is used to determine :

- Ms 0 as the martensite starting temperature when the transformation is complete ;

- $\beta$ which is assumed constant and such that : $Z A(M f)=0.99$ for a complete martensite transformation where Mf is the experimental end of transformation temperature ;

- A and Zs by linear regression from the experimental thermo-metallurgical histories leading to partial martensitic transformation ;

- and, finally, the martensitic transformation critical cooling rate $\mathrm{Tcm}$ (below which no martensitic transformation can occur) as the cooling rate at $700^{\circ} \mathrm{C}$ of the slowest cooling kinetics giving rise to a martensitic transformation.

\subsection{Identification of the ferrito-pearlitic and bainitic transformation model}

For each experimental test $\mathrm{H}^{\mathrm{i}}$ included in CCT diagrams, we know the time history $\mathrm{T}^{\mathrm{i}}(\mathrm{t}$ ) (characterised by six coefficients) and the associated metallurgical evolution $\mathrm{Z}^{\mathrm{i}}(\mathrm{T})$ (which we suppose linear piecewise). Thus, for each thermo-metallurgical histories $\mathrm{H}^{\mathrm{i}}$ we can built a set of specific solutions to the differential equation (for $T \geq M s): \dot{z}(t)=f(T, \dot{T}, z ; d)$ enabling calculation of $\dot{z}\left(E_{k}^{i}\right)=f\left(E_{k}^{i}\right)$ for any thermo-metallurgical state $E_{\mathrm{k}}^{\mathrm{i}}$ of an experimental history $H^{\mathrm{i}}$ [14]. 
So, for any temperature $T$, we can compute the values of function $\boldsymbol{f}$ in the thermo-metallurgical states $E_{\mathrm{T}}^{\mathrm{i}}=\left\{\mathrm{T}, \mathrm{T}^{\mathrm{i}}(\mathrm{T}), \mathbf{z}^{\mathrm{i}}(\mathrm{T}) ; d^{\mathrm{i}}(\mathrm{T})\right\}$ where the $\mathrm{i}$ index indicates experimentally known histories.

Finally, on the basis of the above hypothesis, the identification of the model resume to the CCT diagram data entered which is carried out as follows:

- for each CCT diagram :

- the ferritic transformation quasi-static temperature $\mathrm{Ar}_{3}$;

- the austenitic grain size value $d$;

- the complete martensite transformation starting temperature $\mathrm{Ms}_{0}$;

- the value of the Koistinen-Marbuirger law $\beta$ coefficient ;

- the value of the $A$ and $Z^{S}$ coefficients in equation (3);

- the value of the martensitic transformation critical cooling rate $\dot{T}_{\mathrm{cm}}$.

- for each CCT diagram thermal history :

- the cooling rate at $700^{\circ} \mathrm{C}$;

- the values of the six coefficients characterising, with the cooling rate at $700^{\circ} \mathrm{C}$, each thermal history ;

- the final ferrite, pearlite and bainite proportions ;

- the starting and finishing temperatures for each transformation.

This procedure is the only operation required to identify the metallurgical behaviour of a steel. It is simple and quickly performed by a data entry package, requiring about an hour for fifty or so histories.

\section{RUNNING OF THE MODEL :}

\section{CALCULATION OF $f(T, \dot{T}, z ; d)$ FOR ANY GIVEN STATE}

Knowing $\mathrm{T}, \dot{\mathrm{T}}, \mathbf{z}, \mathrm{Ms}$ and $d$ at a given instant $\mathrm{t}$, we have to determine the values of $\mathbf{z}$ and Ms at a following instant $t+\Delta t$.

- If $\mathbf{T}(\mathbf{t}) \geq \mathbf{A r}_{3}$ :

$$
\dot{z}(t)=0 \quad \text { and } \quad Z_{4}(t+\Delta t)=0
$$

- If $\operatorname{Ar}_{3}>\mathbf{T}(\mathbf{t}) \geq \operatorname{Ms}(t)$ :

$$
\dot{\mathbf{z}}(\mathrm{t}+\Delta \mathrm{t})=\boldsymbol{f}(\mathrm{T}, \dot{\mathrm{T}}, \mathrm{z} ; d) \quad ; \mathrm{Z}_{4}(\mathrm{t}+\Delta \mathrm{t})=0 \quad \text { and } \quad \mathrm{Ms}(\mathrm{t}+\Delta \mathrm{t})=\mathrm{Ms} 0+\mathrm{A}\left[\sum_{\mathrm{i}=1}^{\mathrm{i}=3} \mathrm{Z}_{\mathrm{i}}(\mathrm{t}+\Delta \mathrm{t})-\mathrm{Z}^{\mathrm{s}}\right]^{+}
$$

- If $\mathbf{T}(\mathbf{t})<\operatorname{Ms}(\mathbf{t})$ :

$$
\dot{z}(t)=0 \quad \text { and } \quad Z_{4}(t+\Delta t)=\left[1-\sum_{i=1}^{i=3} Z_{i}(t+\Delta t)\right]\left\{1-\exp \left(\beta \cdot[M s(t+\Delta t)-T(t+\Delta t)]^{+}\right)\right\}
$$

The method applied to calculate $f(T, T, z ; d)$ when $\operatorname{Ar}_{3}>\mathrm{T}(\mathrm{t}) \geq \operatorname{Ms}(\mathrm{t})$ considers $f$ to be smooth and proceeds as follow :

- for all known experimental histories $H^{i}$, the values of function $f$ are calculated for each following thermo-metallurgical states :

$$
\mathscr{E}_{\mathrm{i}}^{1}(\mathrm{~T})=\left\{\mathrm{T}, \dot{\mathrm{T}}^{\mathrm{i}}(\mathrm{T}), \mathbf{z}^{\mathrm{i}}(\mathrm{T}) ; d^{\mathrm{i}}\right\} ; \mathscr{E}_{\mathrm{i}}^{2}(\mathrm{~T}+5) \text { and } \mathscr{E}_{\mathrm{i}}^{3}(\mathrm{~T}-5) ;
$$

- the seven values closest to the current state $\mathcal{E}(t)$ are determined from among the $\mathcal{E}_{j}^{i}(t)(j=1,3)$ defining the metallurgical behaviour of the material in the vicinity of the temperature $T(t)$ by minimising a distance between $\mathscr{E}(t)$ and each $\mathcal{E}_{j}^{i}(t)$;

- the barycentric coordinates of $\mathscr{E}(\mathrm{t})$ with respect to the adjacent values $\mathcal{E}_{\mathrm{v}}(\mathrm{t})(\mathrm{v}=1,7)$ are calculated. The associated linear system is solved with a least squares approach and with selection of the minimum norm solution in the event of a zero determinant ;

- we use only the adjacent $E_{w}(t)(w \leq 7)$ values such that all the barycentric coordinates $\lambda_{w}$ of $\mathcal{E}(t)$ are 
positive (thus $E(t)$ is located within the convex polyhedron based on these points);

- we then calculate : $\quad \dot{\mathbf{z}}(\mathcal{E}(t))=f(\mathcal{E}(t))=\lambda_{w} \cdot f\left[E_{w}(t)\right] \quad$ and finally, we calculate $\mathbf{z}$ at the next time step using an explicit scheme.

\section{VALIDATION WITH EXPERIMENTAL DATA AND COMPARISON WITH THE MODEL OF THE SYSWELD SOFTWARE}

\subsection{Validation principle}

In order to validate the presented model, five series of tests were performed. The first concern was to ensure that the model enables correct simulation of all the tests used for its identification i.e. twenty-nine tests defining the CCT diagram of the 16MND5 (SA 508) steel selected to identify the model [10-14].

Using the same CCT diagram, we defined twenty-eight other thermo-metallurgical histories where the cooling rates differed from those of the histories selected to identify the model. The purpose of this second series of tests is to check the model's capacity to correctly simulate these tests, which are compatible with the identification data but not integrated in them.

In addition, we performed eight dilatometric tests corresponding to atypical thermal evolutions as compared with those used to plot the CCT diagrams. These tests correspond to thermal loading truly undergone at certain points of a structure during quenching and are fairly different from those used for the CCT diagrams. The third and fourth series of tests consist in comparing the model's responses with the experimental results for each of these eight tests, included or not in the identification data of the model. The last series of tests allows to examine the distorsion of the CCT diagram restitution caused by the introduction of the eight atypical tests in the identification data.

Finally, for all this tests, we also have compared the proposed model (denoted by Code Aster in the following tables) with the one proposed by Leblond [11] and introduced in the Sysweld software [14].

\subsection{Restitution of the identification tests}

For these tests, the imposed thermal load and resulting metallurgical response are known. So the first series of tests consists in numerical simulation of these tests and comparison of computed starting and finishing temperatures for each transformation and the final proportions of the constituents formed with the experimental one (cf. table 5.1 and figures 5.1 to 5.4 where the experimental and computed CCT diagrams are superimposed in $\left[\mathrm{T}-\operatorname{Vr}\left(700^{\circ} \mathrm{C}\right)\right]$ reference frame.

\begin{tabular}{|c|c|c|c|c|c|c|c|c|c|c|c|c|}
\hline \multirow[b]{3}{*}{ Constituent } & \multicolumn{4}{|c|}{$\Delta \mathrm{T}$ at $1 \%$ in ${ }^{\circ} \mathrm{C}$} & \multicolumn{4}{|c|}{$\Delta T$ at $Z$ final $-1 \%$ in ${ }^{\circ} \mathrm{C}$} & \multicolumn{4}{|c|}{$\Delta Z$ final in $\%$} \\
\hline & \multicolumn{2}{|c|}{ Code Aster } & \multicolumn{2}{|c|}{ Sysweld } & \multicolumn{2}{|c|}{ Code Aster } & \multicolumn{2}{|c|}{ Sysweld } & \multicolumn{2}{|c|}{ Code Aster } & \multicolumn{2}{|c|}{ Sysweld } \\
\hline & $\max$ & mean & $\max$ & mean & $\max$ & mean & $\max$ & mean & $\max$ & mean & $\max$ & mean \\
\hline Ferrite & 1 & 0,42 & 4 & 2,2 & 10 & 2,58 & 5 & 3,1 & 0,7 & 0,14 & 0,3 & 0,03 \\
\hline Bainite & 4 & 1,37 & 35 & 10,7 & 9 & 3,04 & 32 & 10,3 & 2,3 & 0,7 & 1,9 & 0,3 \\
\hline Martensite & 5 & 1,21 & 16 & 6,1 & - & - & - & - & 2,1 & 0,7 & 0,4 & 0,2 \\
\hline
\end{tabular}

Table 5.1 : Maximum and mean discrepancies between experimental and computed data for twenty-nine model identification tests.

To simplify quantification of the experimental versus computed result deviations, we define, for a given test $\mathrm{n}$, the overall discrepancy on the transformation starting and finishing temperatures and on the final composition by (cf. table 5.2):

$$
\Delta T d n=\Sigma_{i}\left(T_{i}^{n}-T^{\prime} d_{i}^{n}\right) \cdot Z^{\prime} f_{i}^{n} ; \Delta T f n=\Sigma_{i}\left(T f_{i}^{n}-T^{\prime} f_{i}^{n}\right) \cdot Z^{\prime} f_{i}^{n} \text { and } \Delta Z f n=\Sigma_{i}\left(Z f_{i}^{n}-Z f_{i}^{\prime n}\right) \cdot Z^{\prime} f_{i}^{n}
$$

where $\mathrm{Td}_{i}^{\mathrm{n}}$, $\mathrm{Tf}_{\mathrm{i}}^{\mathrm{n}}$ and $\mathrm{Zf}_{\mathrm{i}}^{\mathrm{n}}(\mathrm{i} \doteq 1$ to 4$)$ are the transformation starting and finishing temperatures and the final composition corresponding to a given numerical test $n$ and $T^{\prime} d_{i}^{n}, T^{\prime} f_{i}^{n}$ and $Z^{\prime} f_{i}^{n}$ are the same variables corresponding to a given experimental test $\mathbf{n}$. 


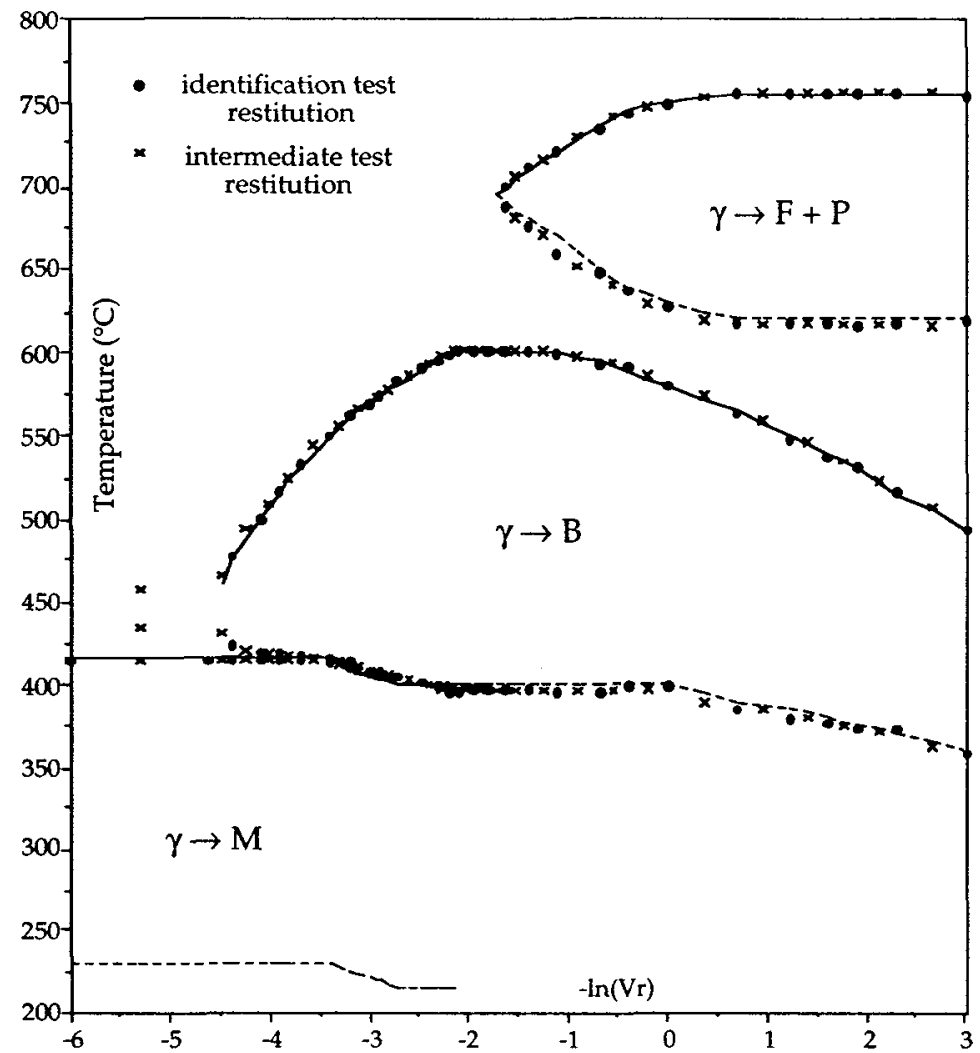

Figure 5.1 : Comparison for the proposed model between experimental and simulated transformation starting and finishing temperatures for the twenty-nine identification tests and the twenty-eight intermediate tests.

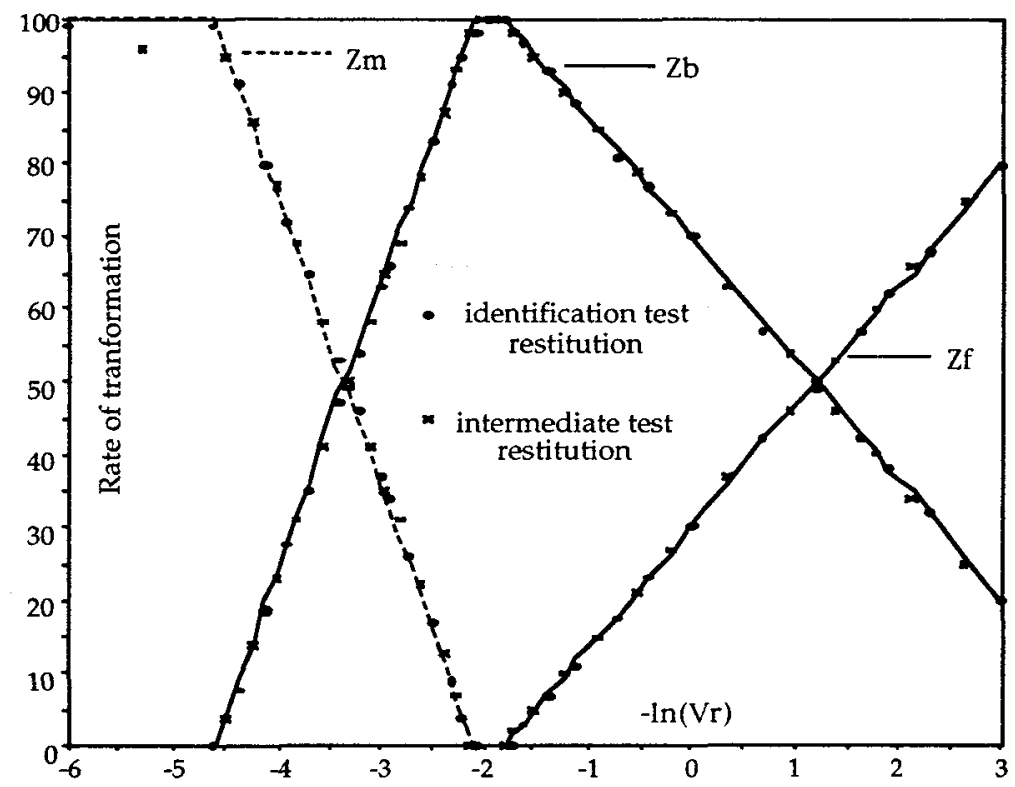

Figure 5.2 : Comparison for the proposed model between experimental and simulated final proportions of phases formed for the twenty-nine identification tests and the twenty-eight intermediate tests. 


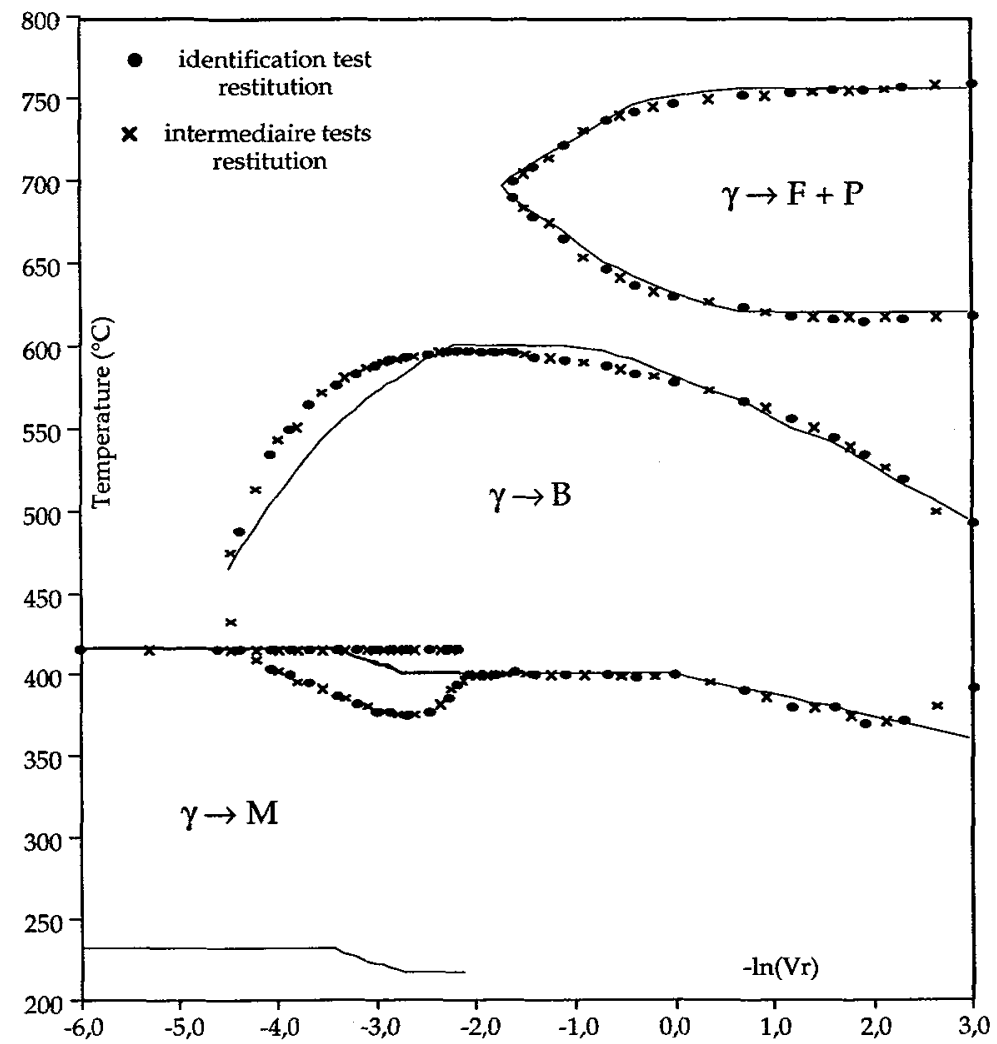

Figure 5.3 : Comparison for the Sysweld's model between experimental and simulated transformation starting and finishing temperatures for the twenty-nine identification tests and the twenty-eight intermediate tests.

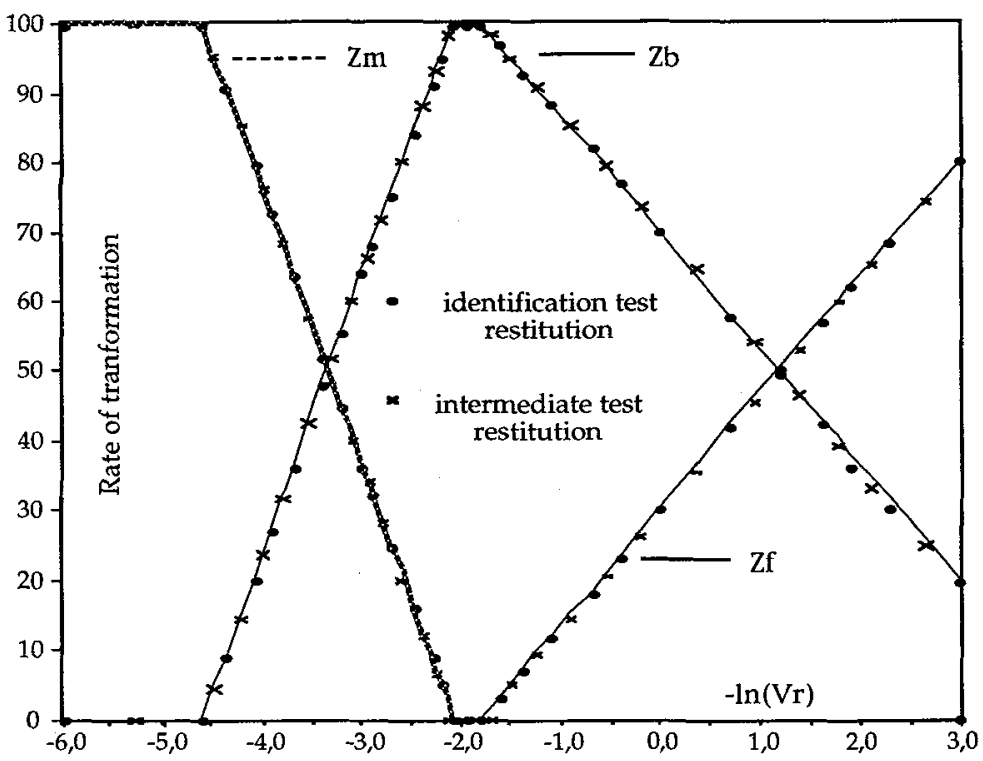

Figure 5.4 : Comparison for the Sysweld's model between experimental and simulated final proportions of phases formed for the twenty-nine identification tests and the twenty-eight intermediate tests. 


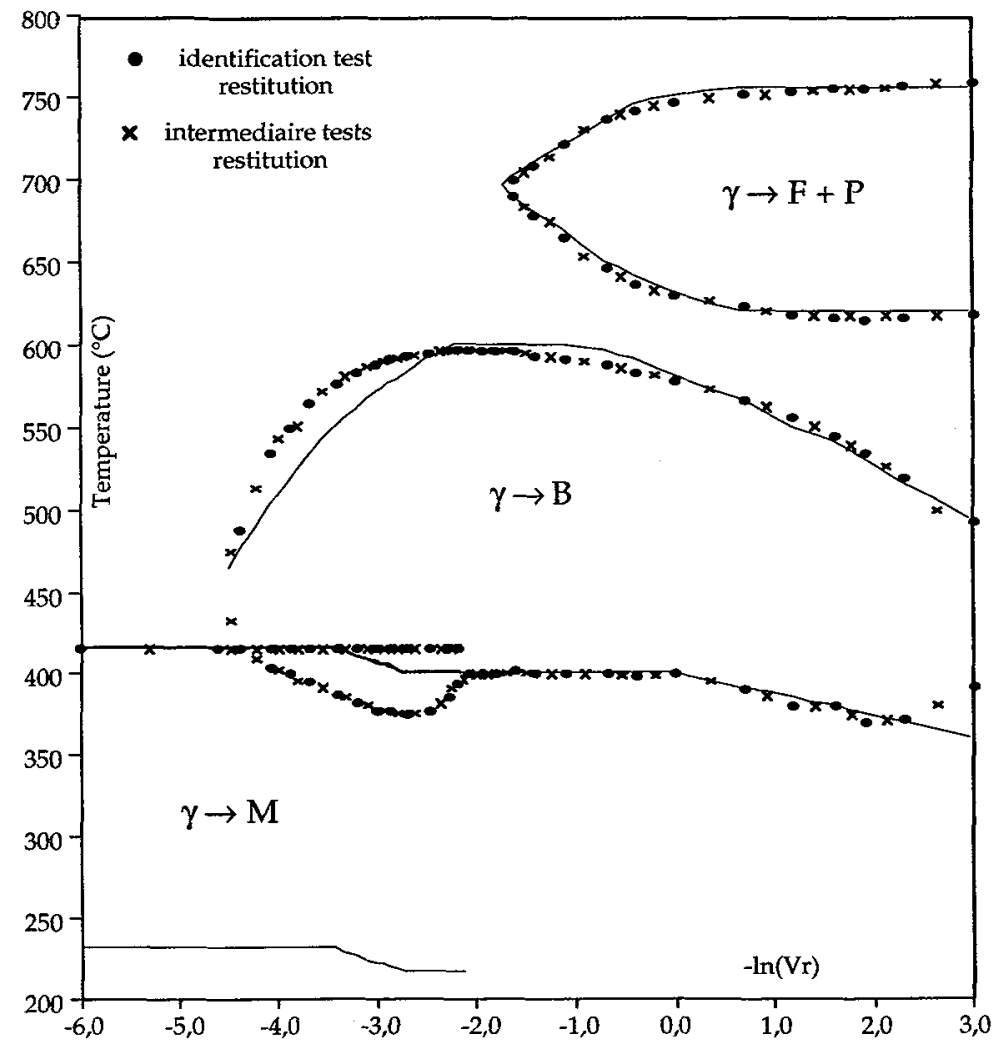

Figure 5.3 : Comparison for the Sysweld's model between experimental and simulated transformation starting and finishing temperatures for the twenty-nine identification tests and the twenty-eight intermediate tests.

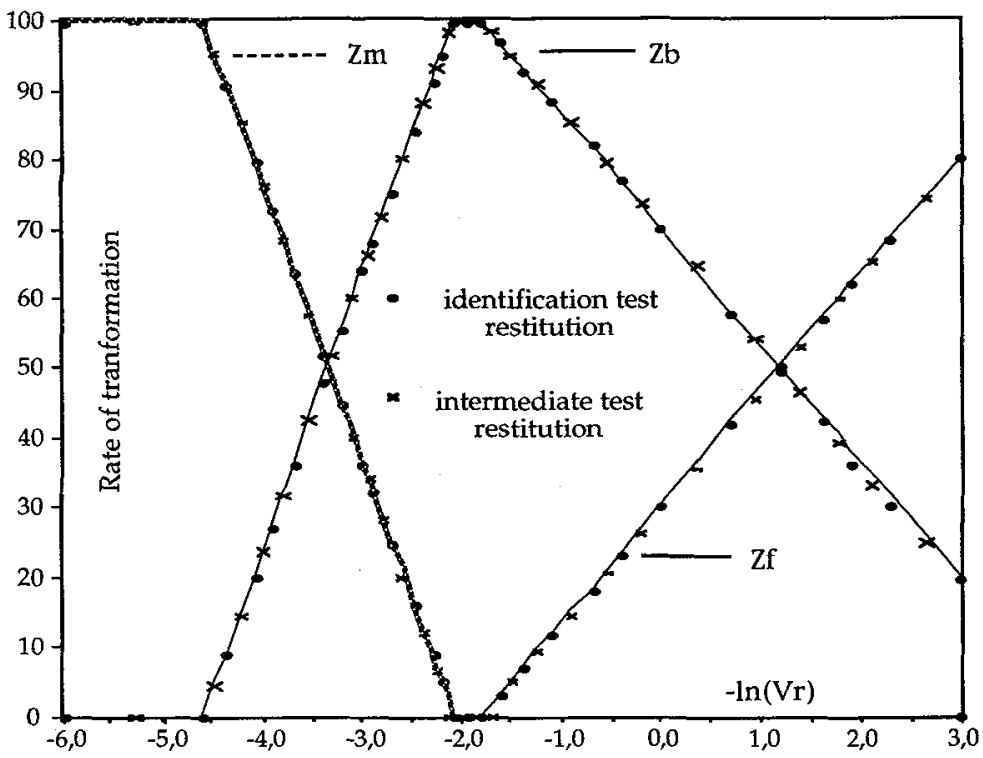

Figure 5.4 : Comparison for the Sysweld's model between experimental and simulated final proportions of phases formed for the twenty-nine identification tests and the twenty-eight intermediate tests. 


\begin{tabular}{|c|c|c|c|c|c|}
\hline \multicolumn{2}{|c|}{$\Delta \mathrm{TD}\left({ }^{\circ} \mathrm{C}\right)$} & \multicolumn{2}{c|}{$\Delta \mathrm{TF}\left({ }^{\circ} \mathrm{C}\right)$} & \multicolumn{2}{c|}{$\Delta \mathrm{ZF}(\%$ absolute) } \\
\hline Aster & Sysweld & Aster & Sysweld & Aster & Sysweld \\
\hline 0,97 & 6,03 & 2,63 & 5,78 & 0,57 & 0,16 \\
\hline
\end{tabular}

Table 5.2: Mean overall errors on simulation of the twenty-nine tests in the model identification CCT diagram.

The conclusion on this first series of tests is that the model simulates perfectly, and at less as well as the one of Sysweld, the tests used for its identification. Indeed, the discrepancies observed between experimental and computed results are of the same order of magnitude as the accuracy (and significance) of the experimental data, in a context where cooling rates range from $-0.05^{\circ} \mathrm{C} / \mathrm{s}$ to $-400^{\circ} \mathrm{C} / \mathrm{s}$.

Based on our experience, we can evaluate to about an half day the requiring time to identify the proposed model. On the other hand, the determination of the Syweld's model parameters has required about two months and appeared more difficult.

\subsection{Restitution of other tests derived from the CCT identification diagrams}

For this second series of tests, we used twenty-eight other thermo-metallurgical histories, taken from the CCT identification diagram but not used for the model identification. Each of these additional tests is characterised by a cooling rate equal to the root mean squares value for the rates in two consecutive histories used for model identification and should yield transformation starting and finishing temperatures and final proportions equal to the average values for the two consecutive CCT diagram histories. For each of these "intermediate" histories, the procedure is as described in 5.2 and numerical and experimental results are compared (cf. tables 5.3 and 5.4 and figures 5.1 and 5.2).

\begin{tabular}{|c|c|c|c|c|c|c|c|c|c|c|c|c|}
\hline & \multicolumn{4}{|c|}{$\Delta \mathrm{T}$ at $1 \%$ in ${ }^{\circ} \mathrm{C}$} & \multicolumn{4}{|c|}{$\Delta \mathrm{T}$ at Zfinal $-1 \%$ in ${ }^{\circ} \mathrm{C}$} & \multicolumn{4}{|c|}{$\Delta$ Zfinal in $\%$} \\
\hline & \multicolumn{2}{|c|}{ Code Aster } & \multicolumn{2}{|c|}{ Sysweld } & \multicolumn{2}{|c|}{ Code Aster } & \multicolumn{2}{|c|}{ Sysweld } & \multicolumn{2}{|c|}{ Code Aster } & \multicolumn{2}{|c|}{ Sysweld } \\
\hline Constituent & $\max$. & mean. & $\max$ & mean. & $\max$ & mean. & $\max$ & mean. & $\max$. & mean. & $\max$. & mean. \\
\hline Ferrite & 2,5 & 0,86 & 3,5 & 1,8 & 8 & 4,27 & 6 & 2,7 & 1,2 & 0,51 & 0,6 & 0,3 \\
\hline Bainite & 7,5 & 2,02 & 34,5 & 10,8 & 16 & 3,27 & 28 & 10,2 & 3,2 & 0,75 & 2 & 0,3 \\
\hline Martensite & 6 & 2,04 & 15 & 7,1 & - & - & - & - & 3,9 & 0,95 & 1,6 & 0,5 \\
\hline
\end{tabular}

Table 5.3 : Maximum and mean discrepancies between computed and experimental results for the twenty-eight tests not used for model identification.

For these tests, the maximum, mean and mean overall errors are, for both models, almost as slight as those observed for the identification tests and we can consider that for both, the interpolation accuracy between the identification data is good.

\begin{tabular}{|c|c|c|c|c|c|}
\hline \multicolumn{2}{|c|}{$\Delta \mathrm{TD}\left({ }^{\circ} \mathrm{C}\right)$} & \multicolumn{2}{c|}{$\Delta \mathrm{TF}\left({ }^{\circ} \mathrm{C}\right)$} & \multicolumn{2}{c|}{$\Delta \mathrm{ZF}(\%$ absolute) } \\
\hline Aster & Sysweld & Aster & Sysweld & Aster & Sysweld \\
\hline 1,47 & 6,2 & 2,28 & 5,7 & 0,69 & 0,36 \\
\hline
\end{tabular}

Table 5.4 : Mean overall errors or simulation of the twenty-eight tests not used for model identification.

The conclusion of this second series of tests is that the model very accurately reproduces the experimental data contained in the CCT used for its identification and even for thermo-metallurgical histories not used for this purpose. In other words, if a CCT diagram characterised by a certain number of histories is integrated in the model, the latter will correctly simulate any history derivable from the diagram considered.

\subsection{Simulation of atypical tests}

The eight atypical dilatometric tests were performed on samples from the same origin, having been subjected to the same austenitization cycle as those used to plot the CCT diagram [5]. These tests correspond to thermal loading truly undergone at certain points of a structure during quenching and are fairly different from those used for the CCT diagrams. In particular, their cooling rates is not constant. We first si- 
mulated them with the models identified only on the basis of the CCT diagram data. The results of these tests are shown in table 5.5.

Experimental-computed data concordance is relatively satisfactory and quite close for both models. More precisely, for the eight tests, the kind of transformations and the main of them was found by the both models.

\begin{tabular}{|c|c|c|c|c|c|c|c|c|c|c|c|}
\hline \multicolumn{4}{|c|}{$\Delta \mathrm{TD}\left({ }^{\circ} \mathrm{C}\right)$} & \multicolumn{4}{|c|}{$\Delta \mathrm{TF}\left({ }^{\circ} \mathrm{C}\right)$} & \multicolumn{4}{|c|}{$\Delta \mathrm{ZF}$ (\% absolute) } \\
\hline \multicolumn{2}{|c|}{ Aster } & \multicolumn{2}{|c|}{ Sysweld } & \multicolumn{2}{|c|}{ Aster } & \multicolumn{2}{|c|}{ Sysweld } & \multicolumn{2}{|c|}{ Aster } & \multicolumn{2}{|c|}{ Sysweld } \\
\hline mean & max. & mean & $\max$ & mean & $\max$ & mean & $\max$ & mean & $\max$. & mean & $\max$. \\
\hline 32,7 & 51 & 25,7 & 50 & 18,5 & 33 & 16,2 & 28 & 14,2 & 25 & 6,9 & 15 \\
\hline
\end{tabular}

Table 5.5: Mean and maximum overall errors on simulation of eight atypical tests with the CCT diagram identified model.

Nevertheless, there are some fairly significant errors and the data contained in the CCT diagrams is probably inadequate for exhaustive characterisation of the metallurgical behaviour of steels during cooling. However, as regards prospects of using the model in a full-scope modelling system (thermal, metallurgical and mechanical), these results would appear relatively satisfactory.

In order to see, on the one hand, whether these atypical test data are compatible for the model with conventional test results and, on the other hand, whether the model can assimilate them, we identified the model with all the experimental data (twenty-nine conventional tests and eight atypical tests) and then resimulated the eight atypical tests (cf. Table 5.6) and the CCT diagram (cf. Table 5.7).

\begin{tabular}{|c|c|c|c|c|c|c|}
\hline & \multicolumn{2}{|c|}{$\Delta \mathrm{TD}$} & \multicolumn{2}{c|}{$\Delta \mathrm{TF}$} & \multicolumn{2}{c|}{$\Delta \mathrm{ZF}$ (absolute) } \\
\hline Model identified & Aster & Sysweld & Aster & Sysweld & Aster & Sysweld \\
\hline with 29 tests & 32,7 & 26,0 & 18,5 & 16,5 & 14,2 & 6,9 \\
\hline with 37 tests & 17,6 & & 4 & & 3,2 & \\
\hline
\end{tabular}

Table 5.6: Mean overall errors on simulation of the eight atypical tests with the model identified using the CCT diagram and the atypical test data.

For the proposed model, the only necessary operation in order to take into account these tests in the identification data is their data capture with the CCT diagram entry package which needs about two hours. On the other hand, we do not succeed to take into account this new data in the identification ones of the Sysweld's model and the fourth and fifth series of tests were only performed with the proposed model.

So, it is to be noted that atypical tests can be included in the identification data, thereby considerably reducing the mean overall errors on simulation of these atypical tests. It is moreover quite clear that the atypical test data are not perceived by the model as being incompatible with those from the twenty-nine conventional identification tests. Their inclusion in the model identification data in no way impairs the quality of simulation of the twenty-nine conventional tests, for which the mean overall errors remain strictly comparable to those obtained with a model identified using only these constant cooling rate tests.

\begin{tabular}{|c|c|c|c|c|c|c|}
\hline & \multicolumn{2}{|c|}{$\Delta \mathrm{TD}\left({ }^{\circ} \mathrm{C}\right)$} & \multicolumn{2}{c|}{$\Delta \mathrm{TF}\left({ }^{\circ} \mathrm{C}\right)$} & \multicolumn{2}{c|}{$\Delta \mathrm{ZF}(\%$ absolute) } \\
\hline Model identified & Aster & Sysweld & Aster & Sysweld & Aster & Sysweld \\
\hline with 37 tests & 1,27 & - & 3,74 & - & 2,58 & - \\
\hline
\end{tabular}

Table 5.7 : Mean overall errors on CCT simulation with the model identified with the CCT diagram and with the model identified with the CCT diagram and the atypical test data.

\section{CONCLUSION}

We have proposed a metallurgical behaviour model for steel cooling. Its originalities are to include $\dot{\mathbf{T}}$ among its variables, to not suppose any particular form of the metallurgical evolution function and to require only primary data such as the CCT diagrams for its identification. 
The validation elements presented, including more of hundred tests, show that, since the model is identified with CCT diagram data, it is able to well simulate all thermo-metallurgical histories derivable from this diagram, even those not used for its identification. If the metallurgical behaviour of steel tested under certain "atypical" conditions was perceived by the model as being not entirely compatible with conventional CCT diagram data, the model's response in such cases is nevertheless relatively accurate and would even be entirely acceptable in the context of a full scope model (thermal, metallurgical and mechanical) for welding type operations.

Furthermore, identification of the model would appear to be simple and fast, and compatible with the subsequent inclusion of atypical tests in addition to the conventional CCT diagram identification data. These atypical tests can then be satisfactorily simulated without the experimental-computed data concordance being impaired in the case of simulation of conventional CCT diagram tests.

Since the model was deemed satisfactory, it has been inserted in the EDF thermo-mechanics finite element code (Code Aster ${ }^{(B)}$ ), together with various models described in the relevant literature for simulation of the mechanical effects of metallurgical phenomena, [4-13]. It thus enables full simulation (thermal, metallurgical and mechanical) of operations such as welding or quenching with recording of the residual stresses induced [2-14].

\section{BIBLIOGRAPHICAL REFERENCES}

[1] Aeby-gautier E., Transformations perlitique et martensitique sous contrainte de traction dans les aciers. Thèse de Doctorat ès Sciences Physiques, Institut National Polytechnique de Lorraine (1985).

[2] Andrieux S., Donore A.M., Waeckel F., A new thermo-metallurgical model for welding and quenching computations. 12th SMIRT, (1993) Stuttgart.

[3] Coleman B.D., Gurtin M.E., Thermodynamics with internal state variables. Journal of chemical physics, vol.47, $\mathrm{n}^{\circ} 2,(1967)$ pp. 597-613.

[4] Donore A.M., Waeckel F., Modélisation élasto-plastique prenant en compte des transformations métallurgiques. Manuel de référence Code Aster, R4.04.02, EDF-DER (1994).

[5] Evangelista L., Tinker J., Transformations microstructurales de l'acier 18MND5. Projet de Fin d'Etudes ENSAM (1992).

[6] Fernandes F.M.B., Modélisation et calcul de l'évolution de la température et de la micro-structure au cours du refroidissement continu des aciers. Thèse de Docteur de l'Institut National Polytechnique de Lorraine, spécialité Science et Génie des Matériaux (1985).

[7] Giusti J., Contraintes et déformations résiduelles d'origine thermique. Application au soudage et à la trempe des aciers. Thèse de Doctorat d'Etat ès Science Physique, Université Paris 6 (1981).

[8] Inoue T., Inelastic Constitutive Relationships and Applications to Some Thermomechanical Processes Involving Phase Transformations. Thermal Stresses III, Elsevier Science Publishers B.V., (1989) pp. 191-278.

[9] Le Bec P., Massoud J.P., Etude des transformations en refroidissement continu de produits représentatifs de veines sombres observées dans des pièces forgées en acier de type 18MND5. Note EDF-DER, HT-41/NEQ 1613-A (1993).

[10] Leblond J.B., Devaux J.C., A new kinetic model for anisothermal metallurgical transformation in steels including effect of austenitic grain size. Acta Metallurgica, vol.32, nº 1 , (1984) pp. 137-146.

[11] Marigo J.J., Le comportement thermo-mécanique des milieux simples à variables mémoratrices : I Généralités et premiers exemples. Note Interne EDF - DER HI/5147-07 (1985).

[12] Waeckel F., Andrieux S., Une relation de comportement métallurgique des aciers au refroidissement. Manuel de référence du Code Aster, R4.04.01, EDF-DER (1992).

[13] Waeckel F., Dupas P., Comparaison des modèles de comportement métallurgiques implantés dans le Code Aster et dans Sysweld. Note EDF-DER HI-74/94/076/0 HT 26/94/033/A (1994).

[14] Waeckel F., Une loi de comportement thermo-métallurgique des aciers pour le calcul mécanique des structures. Thèse de Doctorat ès Mécanique, ENSAM Paris (1994). 